\title{
Is Acoustic Stapedius Reflex Altered by Propofol Anesthesia in Children? A Pediatric Observational Case-control Prospective Study Protocol Claudine Kumba (10) \\ Department of Pediatric Anesthesia and Critical Care, Necker Enfants Malades University Hospital, Paris, France
}

\section{Abstract}

Background: Neurophysiological tests like evoked potentials are diagnostic methods used for monitoring under certain surgery like scoliosis or cochlear implant surgery. It has been demonstrated that these neurophysiological tests can be altered by anesthetics like halogenated drugs.

Objective: This protocol study describes the trial which will be undertaken to determine whether propofol alters the acoustic stapedius reflex during neurophysiological studies in children under anesthesia.

Methods: observational case-control study in children under 18 years scheduled for auditory evoked potential under anesthesia.

Conclusion: This study will determine whether propofol anesthesia alters acoustically induced stapedius reflex in children.

\section{Introduction}

In some pediatric tertiary centers, several neurophysiological tests are realized among which are done under general anesthesia in children for practical reasons such as the necessity for the patient to remain immobile during the tests which can last for several hours. Some of these tests such as electrically induced stapedius reflex are used for monitoring during surgery like cochlear implants [1].

Some of these tests are auditory evoked potentials. There is evidence that general anesthesia with halogenated agents alter electrically induced stapedius reflex in children during cochlear implants surgery [2]. Inhalational agents alter more in a dose dependent manner electrically induced stapedius reflex than propofol during cochlear implant surgery [2]. Halogenated agents and propofol alter in a dose dependent way mid-latency auditory evoked potentials in children $[3,4]$.

Acoustic stapedius reflex is one of the tests among others used to assess audition [5-7]. Not much evidence exists whether propfol anesthesia alters acoustically induced stapedial reflex in children. This study will be undertaken to answer this question.

Primary Objective is to identify the effect of propofol anesthesia on acoustic stapedius reflex in children. Primary outcome will be the stapedius reflex response acoustically induced.

Population (inclusion criterion): pediatric patients less than 18 years admitted for evoked auditory potentials under anesthesia.

Exclusion criterion: parent refusal

\section{Monocenter and or Multicenter Study}

Parent Informed consent and Ethic Committee Autorisation will be obtained prior to inclusion.

Methods: Each patient will be a case and a control for the study. Each patient will undergo the acoustic stapedial reflex test before general anesthesia and then during general anesthesia. The acoustic stapedial reflex response will be measured before and after propofol anesthesia and analysed to see if there is a statistical difference. General anesthesia will be undertaken with propofol $10 \mathrm{mg} / \mathrm{kg} / \mathrm{h}$ after a bolus of $2-3 \mathrm{mg} /$ $\mathrm{kg}$ to maintain the patients under spontaneous ventilation. Patients are monitored using pulse oximetry, heart rate with electrocardiogram and capnometer (non invasive blood pressure measurements interfere with the neurophysiologic measurements and so it is not used continuously for monitoring). Patients will be left under spontaneous breathing through an oxygen mask delivering $61 / \mathrm{min}$.

\section{Statistical Analysis}

Student's t test will be used for univariate statistical analysis between the cases and the controls, multivariate analysis will be also used to assess for independent factors which could explain the differences among the patients (age, gender, comorbidities, premedication with midazolam, clonidine, weight, height, quantity of propofol/ $\mathrm{kg}$ administered, medications...). This multivariate analysis will be realized in the entire cohort before and after propofol anesthesia to assess for independent predictive variables which can influence the acoustic stapedial reflex response with or without anesthesia.

Number of patients to be included: $194-200$

\section{Conclusion}

This case control observational study was will be undertaken to determine whether acoustically induced stapedius reflex is altered by propofol anesthesia.

\section{Competing Interests}

The author declared no competing interests.

"Corresponding Author: Dr. Claudine Kumba, Department of Pediatric Anesthesia and Critical Care, Necker Enfants Malades University Hospital, Paris, France; E-mail: claudine.kumba@gmail.com

Citation: Kumba C (2019) Is Acoustic Stapedius Reflex Altered by Propofol Anesthesia in Children? A Pediatric Observational Case-control Prospective study Protocol. Int J Pediatr Neonat Care 5: 157. doi: https://doi.org/10.15344/24552364/2019/157

Copyright: (C) 2019 Kumba. This is an open-access article distributed under the terms of the Creative Commons Attribution License, which permits unrestricted use, distribution, and reproduction in any medium, provided the original author and source are credited. 
Citation: Kumba C (2019) Is Acoustic Stapedius Reflex Altered by Propofol Anesthesia in Children? A Pediatric Observational Case-control Prospective study Protocol. Int J Pediatr Neonat Care 5: 157. doi: https://doi.org/10.15344/2455-2364/2019/157

\section{References}

1. Andrade KC, Leal Mde C, Muniz LF, Menezes Pde L, Albuquerque KM, et al. (2014) The importance of electrically evoked stapedial reflex in cochlear implant. Braz J Otorhinolaryngol 80: 68-77.

2. Crawford MW, White MC, Propst EJ, Zaarour C, Cushing S, et al. (2009) Dose-Dependent Suppression of the Electrically Elicited Stapedius Reflex by General Anesthetics in Children Undergoing Cochlear Implant Surgery. Anesth Analg 108: 1480-1487

3. Feuerecker M, Lenk M, Flake G, Edelmann-Gahr V, Wiepcke D, et al. (2011) Effects of increasing sevoflurane MAC levels on mid-latency auditory evoked potentials in infants, schoolchildren, and the elderly. BJA 107: 726734.

4. Kuhnle GE, Hornuss C, Lenk M, Salam AP, Wiepcke D, et al. (2013) Impact of propofol on mid-latency auditory-evoked potentials in children. BJA 110: 1001-1009.

5. Attoni TM, Mota HB (2010) Study and analysis of contralateral acoustic reflex in children with phonological disorder. Braz J Otorhinolaryngol 76: 231-237.

6. Pérez-Villa YE, Mena-Ramírez ME, Aguirre LE, Mora-Magaña I, GutiérrezFarfán IS, et al. (2014) Diagnostic Utility of the Acoustic Reflex in Predicting Hearing in Paediatric Populations. Acta Otorrinolaringol Esp 65: 332-338.

7. Counter SA, Buchanan LH, Ortega F (2012) Acoustic Stapedius Muscle Reflex in Mercury-Exposed Andean Children and Adults. Acta Otolaryngol 132: 51-63. 